\title{
Modification of used commercial reverse osmosis membranes to nanofiltration modules for the production of mineral-rich packaged drinking water
}

\author{
B. Govardhan ${ }^{1,2} \cdot$ S. Fatima ${ }^{1,2} \cdot$ M. Madhumala ${ }^{1} \cdot$ S. Sridhar ${ }^{1,2}$
}

Received: 28 April 2020 / Accepted: 2 October 2020 / Published online: 23 October 2020

(C) The Author(s) 2020

\begin{abstract}
Global supply of commercial reverse osmosis (RO) membranes is growing exponentially due to rapid population growth, industrialization, and urbanization. The continuous demand for enormous quantity of drinking water has brought about process improvements and technological advancements in membrane preparation. The transformation of used RO membranes into nanofiltration (NF) and ultrafiltration membranes by opening up the pores using chemical treatment by inexpensive oxidizing agents could be one of the cost-effective options. The present study investigates the chemical oxidation of the indigenously synthesized $\mathrm{RO}$ membrane using aqueous sodium hypochlorite $(\mathrm{NaOCl})$. The performance of the membrane was evaluated by conducting experiments under varying operating conditions of operating time, feed pressure, and total dissolved solids (TDS) in raw water for calculation of flux and salt rejection (\%). From an initial flux of $25.2 \mathrm{~L} / \mathrm{m}^{2} \mathrm{~h} \mathrm{and}$ TDS rejection of $97.5 \%$ for original RO membrane, the values reached $80 \mathrm{~L} / \mathrm{m}^{2} \mathrm{~h}$ and $25.5 \%$, which is in NF range, after a reaction time of $780 \mathrm{~min}$ with $4000 \mathrm{ppm}$ concentration of $\mathrm{NaOCl}$ oxidizing agent. Further extension of treatment time to $900 \mathrm{~min}$ enhanced the flux to $130 \mathrm{~L} / \mathrm{m}^{2} \mathrm{~h}$ with salt rejection lowering to $5.67 \%$. Membrane cleaning was performed efficiently using an advanced technique in which chlorine dioxide $\left(\mathrm{ClO}_{2}\right)$ was used in combination with citric acid. This combination ensured rapid cleaning with restoration of water flux and \% salt rejection. The process was scaled up to pilot plant level using RO membranes modified to NF range of pore size. Permeate water enriched with minerals was further packed using an indigenously designed semi-automatic bottling unit. The studies revealed that the indigenously developed RO membranes are easy to alter into high-performance NF membranes. Overall, the process for production of packaged drinking water was cost-effective, easy to operate, and environmentally friendly.
\end{abstract}

Keywords Chemically modified reverse osmosis membrane $\cdot$ Hypo $\cdot$ Nanofiltration and ultrafiltration $\cdot$ Flux and \%rejection $\cdot$ Cost estimation $\cdot$ Process and bottling unit

\section{Introduction}

Rapid urbanization and population growth in the globe have caused large-scale exploitation of ground and surface water. The two major concerns for drinking water are its scarcity and treatment, which can be solved by pressure-driven

S. Sridhar

sridhar11in@yahoo.com

1 Membrane Separations Laboratory, Process Engineering and Technology Transfer Division, CSIR-Indian Institute of Chemical Technology, Hyderabad 500007, India

2 AcSIR, Academy of Scientific and Innovative Research, Ghaziabad 201002, India membrane processes, namely reverse osmosis (RO), nanofiltration (NF), and ultrafiltration (UF) (Pangarkar et al. 2011). In the current scenario, the global market is constantly expanding with newer materials for the production of commercial membranes, such as cellulose acetate (CA), cellulose diacetate (CDA), polyvinylidene fluoride (PVDF), polyethersulfone (PES), polyacrylonitrile (PAN), and polyamide-based thin-film composites (TFC) made of polyamide (PA), due to continuous process improvements in the purification of water and wastewater treatment (Lee et al. 2011). Zhou and Song (2005) studied the water flux and salt rejection rate using a CA-based commercial RO membrane for a synthetic salt solution (Zhou and Song 2005). Maddah et al. (2018) used PVDF (FP100), PES (ES404), besides low (AFC40)- and high (AFC99)-pressure PA commercial 
membranes for the treatment of red seawater at Rabigh City (Maddah et al. 2018). Graphene oxide membranes were used for enhancing the water purification in terrestrial and space applications by Buelke et al. (2018). Most of the production of commercial membrane in the form of large flat sheets without substantial defects is extremely difficult, especially if additives such as graphene oxide are used and it needs tremendous efforts to bring these membranes to market at low cost. However, the market for PA-TFC-based membranes is already well established, and it has great potential to meet circular economy standards.

Usually, the selection of TFC membranes for the RO process depends on flexibility and optimization of the materials used for the formation of a ultraporous substrate layer and selective thin film layer. PA-TFC membrane is prepared by interfacial polymerization ( $\mathrm{Li}$ et al. 2014) and extensively used in RO process because of its high rejection and flux as well as resistance and stability to high temperature and $\mathrm{pH}$ as compared to other commercial membranes ( $\mathrm{Zi}$ et al. 2019). Mass transfer through the RO membrane occurs by solution-diffusion mechanism as shown in Fig. 1, wherein the hydrostatic pressure causes the flow of preferentially interacting and smaller water molecules from the concentrated to the diluted side, while the solutes are retained by the membrane due to lack of any affinity. In the PA-TFC membrane, the non-porous PA layer acts as a catalyst to absorb the water molecules at the upstream side followed by diffusion through the thickness and desorption at the downstream side by potential chemical difference across the membrane. The persisting limitation of the present generation PA-TFC-based RO membranes is their limited resistance to chemical attack.

The average lifespan of the RO membrane is about $2-5$ years, which mainly depends upon the quality of feed and experimental conditions (Razdan and Shah 2001). The

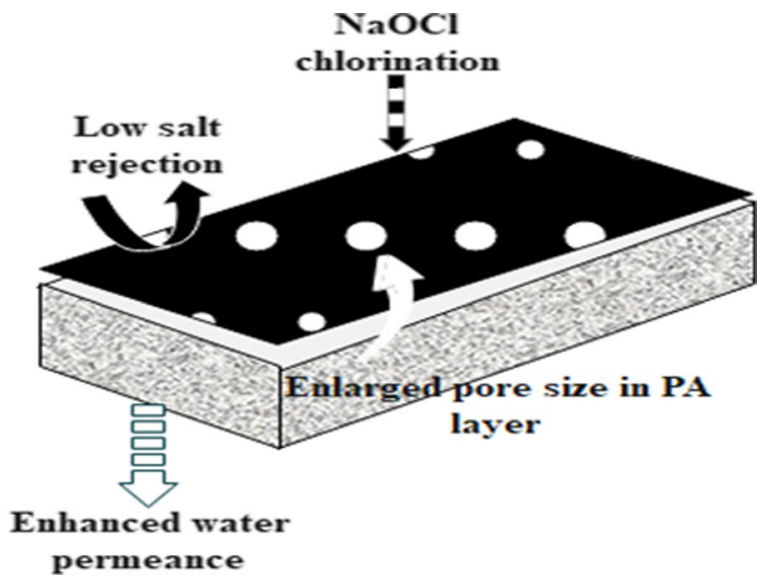

Fig. 1 Mechanism of transport through reverse osmosis membrane modified by hypo used RO membranes are replaced after a fall in membrane performance caused by several factors, i.e., concentration polarization and fouling, requirement of greater operating pressure to overcome the rising osmotic pressure, with subsequent decrease in permeation, and salt rejection (Moshe and Menachem 2007). Therefore, there is a need to develop a method to increase the end of life of used RO membranes, which meet the economic and environmental concerns (Molina et al. 2015). This constraint can be an attractive feature for the recycling of used membranes. Currently, intense research has been done on the remolding of $\mathrm{RO}$ membranes into NF/UF membranes. However, the transformation of the RO membrane into NF by chemical modification using chlorine agents could be an innovative and interesting method that leads to success in academic and industrial levels (Mohammad et al. 2015; Gohil and Suresh 2017). The recovery and recycle of used membranes can be realized by using sodium hypochlorite $(\mathrm{NaOCl})$ as a basic solution to facilitate the re-establishment of the membrane, which is cost-effective, durable, requires less energy and easier methodology compared to purchasing of a new commercial module (Le and Nunes 2016). The chemical transformation of RO into NF/UF membranes is profitable as the scale-up of $\mathrm{NF} / \mathrm{UF}$ membranes into spiral wound module arrangement is very exorbitant as it requires an immense framework in the form of membrane casting and coating machines (Molina et al. 2018; Warsinger et al. 2018).

Fouling is the main cause for the disposal of thousands of tons of RO membranes every year. Usually, end-of-life membranes are handled according to laws and regulations of each country, and membranes may end up in landfills. Direct reuse of membranes is not always feasible due to high membrane fouling. Over the past two decades, several researchers are concentrating on the reuse and recycling possibilities of RO membrane by various treatment methods such as direct recycling of module components, incineration for energy recovery, and oxidative method for chemical conversion into porous membranes (Lawler et al. 2012). Lower tolerance of chlorine by PA could be profited to change membrane morphology and performance. Membranes can be regenerated to compete with commercial membranes in terms of cost, durability, effectiveness, maintenance protocols, and energy requirements. Coutinho de Paula et al. (2017) treated used RO membranes by chemical oxidation method for technical feasibility (Coutinho de Paula et al. 2017), while Moradi et al. (2019) converted end-of-life spiral wound $30 \mathrm{RO}$ membrane to UF membrane bypassing $13,000 \mathrm{ppm} \mathrm{NaOCl}$ solution (Moradi et al. 2019). After that, the UF was transformed into NF by polyelectrolyte layer-by-layer deposition using commercial and low-cost electrolytes, viz. polyethylene imine (MDa 0.1-0.5), acrylate polymer (MDa 5-10). Moron-Lopez et al. (2019) also transformed end-of-life RO membranes to NF and UF by exposing them to $6200 \mathrm{ppm}$ 
and $300,000 \mathrm{ppm}$ of $\mathrm{NaOCl}$ at $\mathrm{pH} 10$, for $24 \mathrm{~h}$ (MoronLopez et al. 2019). As compared to the untreated membrane, the surface characteristics of the transformed membrane were improved along with the removal of fouling. The used RO membranes were chemically treated with hypo solution of 30,000 ppm to remove the PA top layer for the formation of an ultraporous polysulfone UF support layer (Will et al. 2013; Kang et al. 2007), whereas Do et al. (2012) degraded the PA-TFC membranes of NF and RO using the hypo solution (Do et al. 2012). Further, the chemical modification of end-of-life RO membranes converted to NF and UF membranes were tested with acetone/ $N$-methyl-2-pyrrolidone organic solution as well as alkaline feeds for evaluation of membrane performance by García et al. (2015).

The present study investigates the economic strategy for easy alteration of tight $\mathrm{RO}$ membrane into high-performance $\mathrm{NF}$ membranes for secondary application using $\mathrm{NaOCl}$ as a low-cost oxidizing agent. The exposure of $\mathrm{NaOCl}$ on the used RO PA layer helps to open up the pores of the membrane, which leads to NF, and subsequently total disintegration to UF range with further oxidation. Experiments were carried out under varying parameters of operating pressure and time to evaluate flux, salt rejection (\%), and permeate TDS of the modified membranes. Further, the process was scaled up to pilot plant level for packaged drinking water production. A cost estimation of the process was made for $1000 \mathrm{~L} / \mathrm{h}$ capacity.

\section{Materials and methods}

The indigenously synthesized RO membrane of spiral wound modules was obtained from Permionics Membranes Pvt. Ltd., Vadodara, Gujarat, India. Diaphragm (300 GPD) and booster pumps, pressure gauge, and TDS meter were purchased from SVS water solutions, Secunderabad, Telangana, India. $\mathrm{NaOCl}$ of $4 \%(w / v)$ was procured from IL Finar Chemicals Pvt. Ltd., Hyderabad, Telangana, India. Municipal water used as feed in all our experiments was supplied by GHMC, Hyderabad, India. Demineralized water for washing the membrane was produced in house using a double stage RO system. Chemicals used to wash the membranes such as chlorine dioxide $\left(\mathrm{ClO}_{2}\right)$, citric acid, sodium lauryl sulfate (SLS), ethylene diamine tetra acetic acid (EDTA), sodium metabisulfite (SMBS), and sodium hydroxide $(\mathrm{NaOH})$ were purchased from Sri Sai Scientific Hyderabad, Telangana, India. Polyethylene glycol (PEG) with an average molecular weight cut off 20,000 was obtained from Spectrochem Pvt. Ltd., Mumbai, India. Conductivity (DCM-900), Colorimeter (Hach-DR-890, Bangalore, India), and pH meters (DPH504) were supplied by Global Electronics, Hyderabad, Telangana, India, to analyze feed, permeate, and reject samples. Detailed analysis of raw water characteristics is provided in
Table 1. Aqueous hypo solutions of varying concentrations were prepared for modifying the RO membranes. Packaged drinking bottles with lids of various capacities were procured from Mark Pack, Hyderabad, India.

\section{Modification of used RO membrane}

The present innovation deals with controlled chemical conversion of commercial membranes from RO to NF range of pore size using $\mathrm{NaOCl}$ oxidizing agent (Puspitasari et al. 2010). The most commonly used TFC-RO membranes are comprised of aromatic PA skin layer (Fig. 2). Initially, $4000 \mathrm{ppm}$ of dilute $\mathrm{NaOCl}$ solution was prepared by dissolving $20 \mathrm{ml}$ of $4 \% \mathrm{w} / \mathrm{v}$ hypo solution $(40,000 \mathrm{ppm})$ in $1880 \mathrm{ml}$ of deionized water in the ratio of $1: 100$. The salinity of $4000 \mathrm{ppm}$ is approximately $78 \%$ of $\mathrm{NaOCl}$ concentration which comes to $3120 \mathrm{ppm}$. Use of tap water to dope hypo for membrane modification may not give reproducible data due to interference by other ions present in the water. The prepared hypo solution was passed into the feed tank and circulated through PA-TFC RO membrane modules for 30 min using a diaphragm pump installed upstream of the membrane assembly. It was ensured that the hypo solution from reject and permeate lines was recycled to the feed tank. Further, the membrane module was washed thoroughly with water for $30 \mathrm{~min}$ in each run to ensure complete removal of hypo solution from membrane modules and pipelines. Permeate samples were collected every $30 \mathrm{~min}$ to observe the water flux and \% TDS rejection. The experiment was continued until NF region was reached at 30 min duration of hypo exposure for achieving 100 molecular weight cutoff (MWCO) which is about twice the pore diameter of RO membrane, to $780 \mathrm{~min}$ for achieving nearly $1000 \mathrm{MWCO}$, which nears the beginning of UF range. Further, the experiment was continued to reach UF region of negligible TDS rejection, i.e., $900 \mathrm{~min}$. The modified membrane was treated with $0.5 \%$ (w/v) of SMBS solution to remove residual chlorine and prevent further opening of pores, followed by storage in the same SMBS preservative medium. The resultant membranes were found to follow the NF and UF principles in separating the feed components from raw water on the basis of molecular sieving depending upon differences in MWCOs of the desired membrane and used for experimental

Table 1 Detailed characteristics of feed raw water sample

\begin{tabular}{lll}
\hline S. no & Parameter & Sample \\
\hline 1 & Color & Nil \\
1 & Total dissolved solids (TDS) $(\mathrm{mg} / \mathrm{L})$ & 288 \\
2 & $\mathrm{pH}$ & 7.4 \\
3 & Turbidity (FAU) & 1 \\
4 & Conductivity $(\mu \mathrm{s} / \mathrm{cm})$ & 0.45 \\
\hline
\end{tabular}




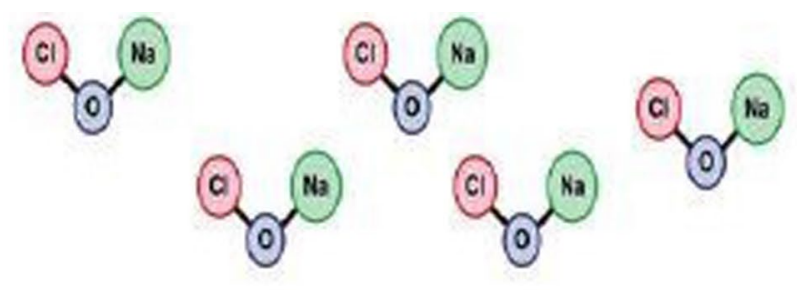

\section{Surface modification}

(Nanofiltration / Ultrafiltration pore structure)

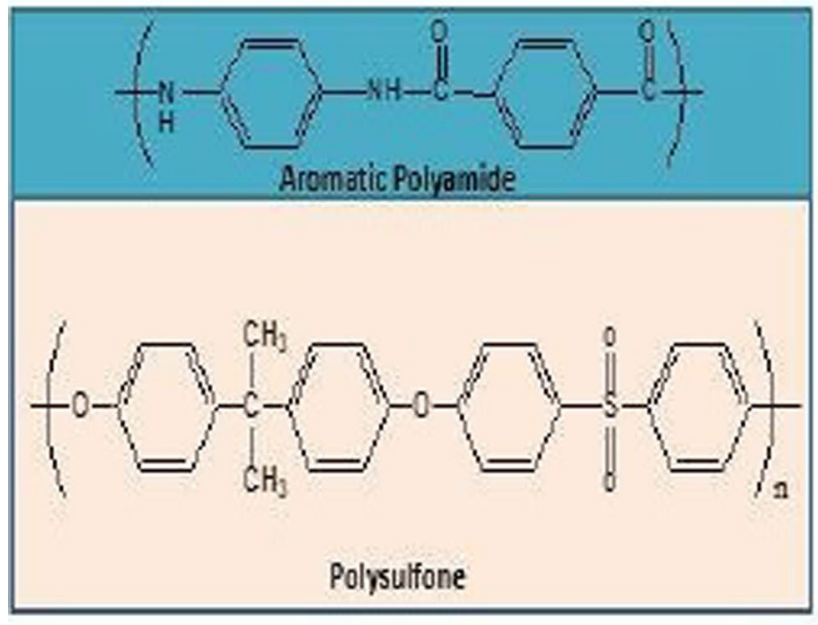

Thin film composite Polyamide Reverse 0smosis Membrane
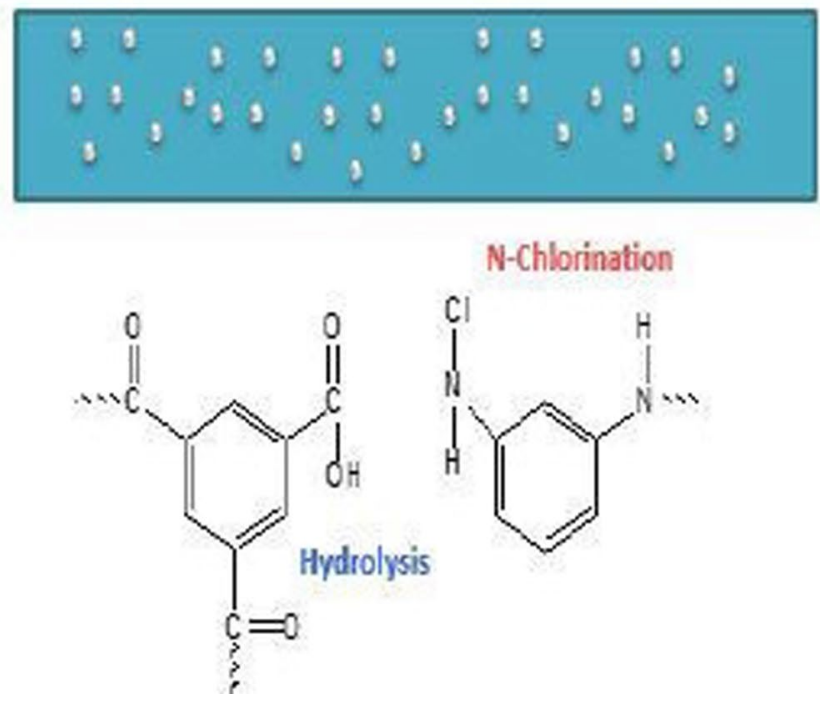

Fig. 2 Schematic representation of chemical transformation of RO to NF membrane

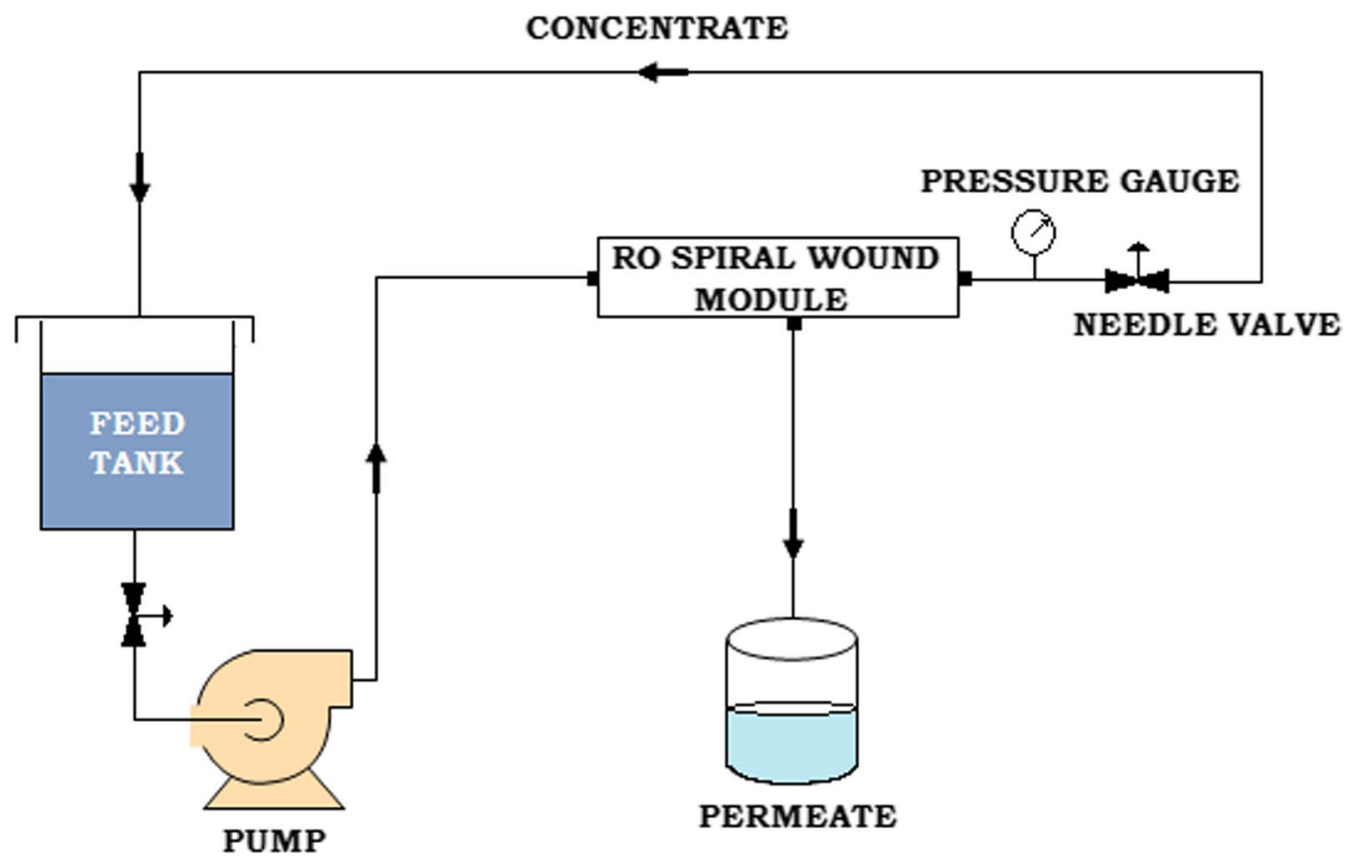

Fig. 3 Schematic of laboratory reverse osmosis system 
studies. Figure 3 shows a schematic representation of the chemical modification of RO into NF/UF membrane.

\section{Membrane characterization studies}

The pristine and modified membranes were characterized by Fourier transform infrared spectroscopy (FTIR), scanning electron microscopy (SEM), and X-ray diffraction (XRD) for structural analysis, morphology and crystalline nature with inter-segmental spacing between polymer chains. FTIR spectrum was obtained in the scanning range of $400-4000 \mathrm{~cm}^{-1}$ wave number with a PerkinElmer 283B FTIR spectrophotometer procured from Boston, MA, USA, using $\mathrm{KBr}$ pellet method. The inter-segmental distance among the monomers of the membrane was evaluated using a powdered X-ray diffractometer (XRD) of model number (Siemens D 5000) using the source of CuK-alpha to produce $\mathrm{X}$-rays of $1.54 \AA$ wavelengths $(\lambda)$. The diffraction angle was varied from $2^{\circ}$ to $60^{\circ}$ on $2 \theta$ scale for the determination of the $d$-spacing values. The surface and cross-sectional morphology of the membrane was studied using a scanning electron microscope of model JEOL JSM 5410, Tokyo, Japan.

\section{Experimental setup for modified RO membrane}

The modified RO membrane used in the experimental studies is depicted in Fig. 4. A feed tank of $5 \mathrm{~L}$ capacity was used through which water was supplied to the membrane system. A diaphragm pump was used to pass the feed through the membrane module to maintain the pressure up to $15 \mathrm{~kg}$ / $\mathrm{cm}^{2}$. The reject obtained from the membrane module was fed back to the feed storage tank through a reject valve. A pressure gauge was used to maintain the pressure of the feed and fixed at the upstream side of the pressure control needle valve, positioned at the reject outlet line. The flow rates of permeate and reject were measured using rotameters.

\section{Experimental procedure for transformation of used RO membranes to NF and UF region}

The experimental setup of the laboratory modified RO membrane system is shown in Fig. 4. Before starting the experiments, the system was run with deionized water to determine the dead volume of the membrane module. The feed tank was filled with $2 \mathrm{~L}$ of aqueous hypo solution with a TDS of $4000 \mathrm{ppm}$ and $\mathrm{pH} 9.8$ before being fed to the used RO spiral membrane module installed within a FRP housing having an effective separation area of 1.2 $\mathrm{m}^{2}$. A diaphragm pump was used to maintain the pressure at $7 \mathrm{~kg} / \mathrm{cm}^{2}$ and employed for circulating the liquid throughout the system. A needle value was provided to restrict the concentrate obtained from the reject outlet, whereas the pressure gauge indicated the pressure of the feed while passing through the membrane module. Permeate was collected in a measuring jar for every $10-20 \mathrm{~s}$ to record the flux. The experiments were conducted by varying the pressure from 0 to $9 \mathrm{~kg} / \mathrm{cm}^{2}$ across a time period of 0-900 min. The modified RO membrane was completely cleaned with demineralized water to remove the excess $\mathrm{NaOCl}$ after every $1 \mathrm{~h}$ of each experiment. For reproducibility, the characteristics of permeate were evaluated by repeating the experiments thrice with each feed

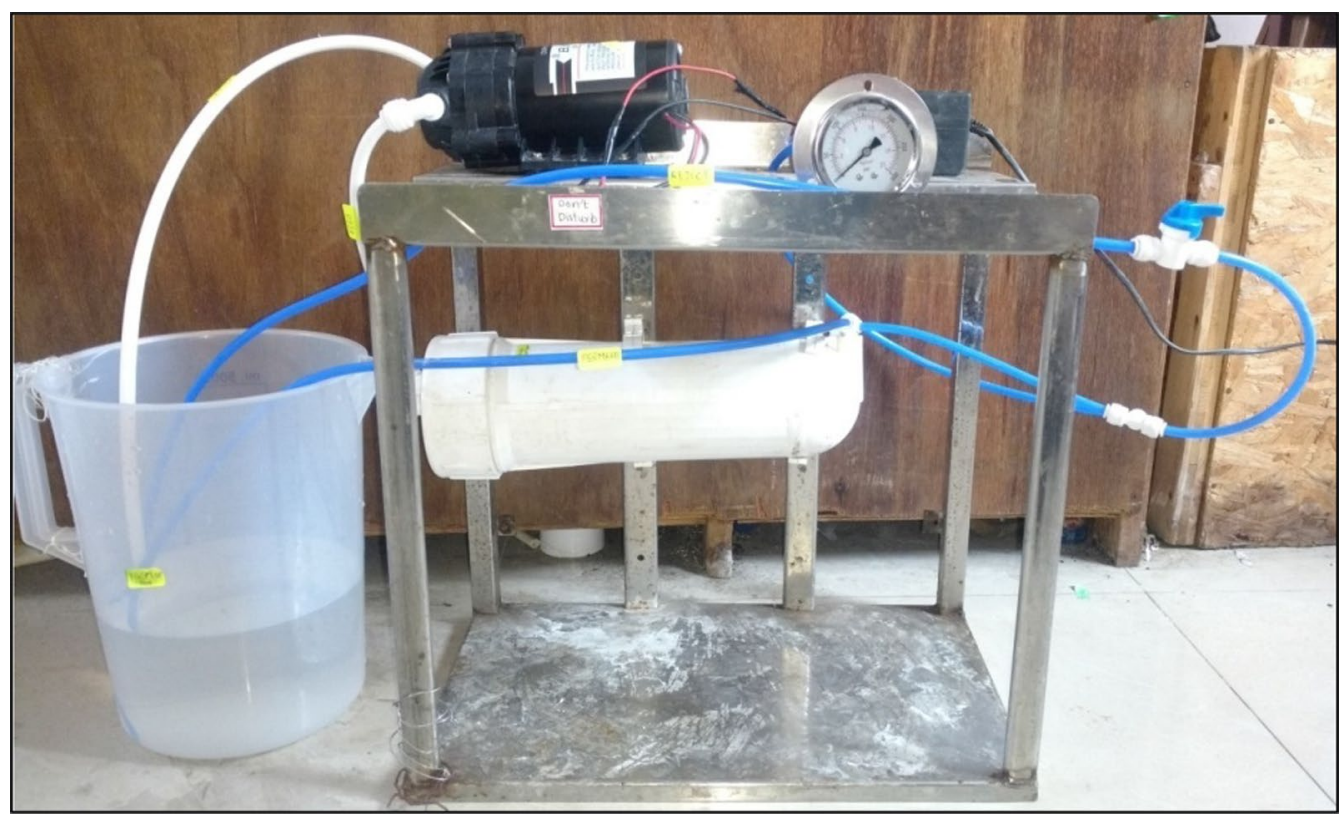

Fig. 4 Experimental setup for modification of RO membrane 
sample, which ascertained the membrane modification was controlled and optimized. Inorganic and organic solutes present in the raw water form scales on the membrane surface, which reduces its life span. Therefore, chemical cleaning was carried out by washing the membrane module thoroughly with demineralized water for 20-min duration, before storage in $0.5 \% \mathrm{w} / \mathrm{v}$ SMBS to prevent biofouling. After modification of the used RO membrane, the resultant NF membrane was used in the pilot plant for the production of packaged drinking water from municipal water (raw water). The results of pilot-scale study are provided in "Pilot-scale studies" section.

\section{Chemical cleaning of used membranes}

Membrane fouling results from scale formation by metal salts with calcium sulfate being the most stubborn to dislodge. Suspended solids and colloidal impurities present in the raw water also foul the membrane. The growth of both aerobic and anaerobic bacteria creates formation of a microbiological film on the membrane surface and pores. This growth causes significant problems on both upstream and downstream of membrane components. Therefore, specific membrane washing procedures were developed by researchers to produce reusable membranes using various reagents such as $\mathrm{ClO}_{2}$, citric acid, sodium lauryl sulfate (SLS), EDTA, $\mathrm{NaOH}$, and SMBS. Membrane cleaning is influenced by the properties of the cleaning solution, i.e., concentration, $\mathrm{pH}$ and temperature, etc. Usually, chlorine is the most regularly utilized biocide and can deactivate the microorganism quickly after washing. On the other hand, it removes the PA layer of TFC by continuous usage resulting in the declination of the water flux. However, $\mathrm{ClO}_{2}$ does not damage the PA layer and proves effective and safer in deactivating the pathogens (Govardhan et al. 2018; Sridhar 2018). The protocols followed for membrane cleaning are as follows:

\section{Acid wash}

The solution containing $1 \% \mathrm{ClO}_{2}, 1 \%$ citric acid, $0.5 \%$ SLS was circulated through the membrane module for $30 \mathrm{~min}$ to remove deposits of organic and inorganic matter, followed by water wash for $15 \mathrm{~min}$.

\section{Alkaline wash}

Alkaline wash was conducted by passing $0.5 \%$ EDTA $+1 \%$ $\mathrm{NaOH}$ in the system for 30 min, which removes organic foulants. After cleaning, the membranes are stored in aqueous SMBS $(0.5 \%)$ solution to prevent formation of biofilm.

\section{Calculation of flux and salt rejection}

The membrane was first cleaned with deionized water, and feed was circulated through the membrane for a certain period of time. The flux and $\%$ salt rejection were calculated from the collected permeate samples using the following equations:

$J_{v}=\frac{\text { Volume of water collected }(\mathrm{L})}{\text { Membrane area }\left(\mathrm{m}^{2}\right) \times \operatorname{Time}(h)}$

$\%$ Rejection $=\left(1-\frac{C_{\mathrm{p}}}{C_{\mathrm{f}}}\right) \times 100$

where $J_{v}$ is water flux, $C_{\mathrm{f}}$ and $C_{\mathrm{p}}$ are the concentrations of solutes (TDS) in feed and permeate samples, respectively.

\section{Analytical studies}

\section{Total Dissolved Solids (TDS)}

TDS indicates non-filterable solids that can easily pass through a filter of $\leq 2 \mu \mathrm{m}$. Known volume $(10 \mathrm{ml})$ of raw water or permeate was taken in a pre-weighed petri dish, which was placed on a sand bath taken in a glass basin. The sand bath was kept on a magnetic hot plate and heated slowly up to a temperature of $105{ }^{\circ} \mathrm{C}$ to evaporate the entire liquid portion. The weight of the petri dish was recorded again to determine the quantity of residual solids present per $10 \mathrm{ml}$, and the calculation was proportionately adjusted to $1 \mathrm{~L}$ to obtain TDS in $\mathrm{mg} / \mathrm{l}$ (ppm).

\section{Turbidity and color}

The turbidity and color of the permeate samples were measured by Turbidity Meter (Hach Colorimeter, Savant Instruments, Hyderabad, India). It works on dual mode, i.e., automatic and manual. The detection range varies from 0.01 to 1100 FAU wherein 1 FAU is equivalent to 1 Nephelometric Turbidity Unit (NTU) of formazin.

\section{Results and discussion}

\section{Characterization of membrane}

\section{Structural analysis of RO membrane by FTIR}

FTIR spectra of the RO membrane before and after modification by $\mathrm{NaOCl}$ are provided in Fig. 5. The peaks observed at $1745.64 \mathrm{~cm}^{-1}, 1672.32 \mathrm{~cm}^{-1}$, and $1535.39 \mathrm{~cm}^{-1}$ represent 


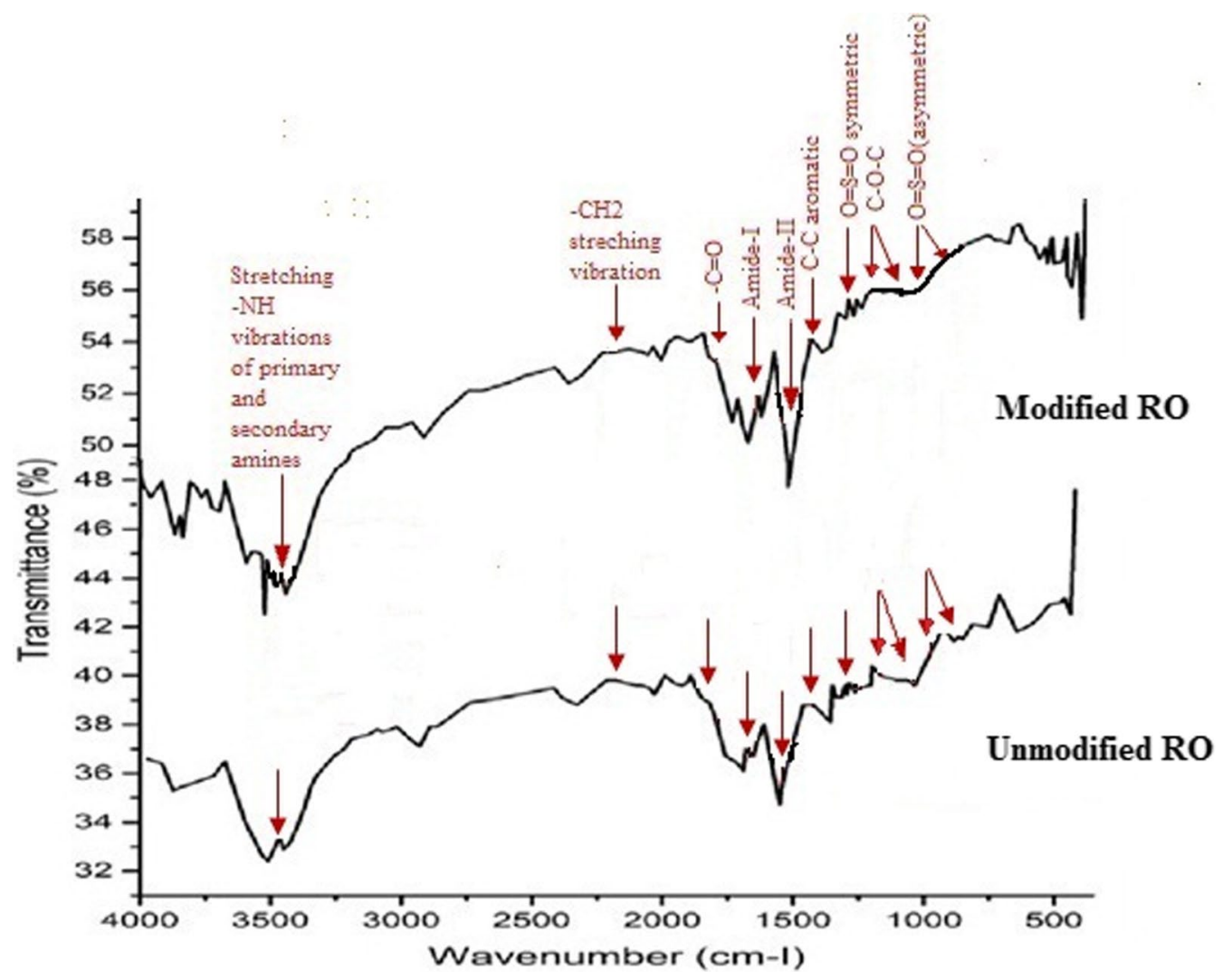

Fig. 5 FTIR analysis of $\mathbf{a}$ pristine and $\mathbf{b}$ modified RO membranes

the $-\mathrm{C}=\mathrm{O}$ group, amide I and II with bending and stretching vibrations of carbonyl amide groups, respectively (Porubská et al. 2012; El Aassar 2012). The $-\mathrm{CH}_{2}$ stretching vibration of the peak is seen at $2376 \mathrm{~cm}^{-1}$ with corresponding-NH stretching vibration occurring at $3446.91 \mathrm{~cm}^{-1}$ which are associated with the primary and secondary amines connected with terminal amine groups. The characteristic peaks of $1481,1398,1288,1244$, and $1172-1016 \mathrm{~cm}^{-1}$ are attributed to aromatic $\mathrm{C}-\mathrm{C}$, symmetric $\mathrm{O}=\mathrm{S}=\mathrm{O}$, ether $\mathrm{C}-\mathrm{O}-\mathrm{C}$, and asymmetric $\mathrm{O}=\mathrm{S}=\mathrm{O}$ group stretching vibrations of PES support layer of the composite membrane, respectively (Tin et al. 2003; Venkata et al. 2016). The intensity of the peaks of amides I and II was found to decrease from the original RO (Fig. 5a) to the chemically modified RO membrane (Fig. 5b), which indicates the degradation of the amide group after chlorination by $\mathrm{NaOCl}$. The degradation mechanism (Scheme 1a) in the PA membrane mainly includes two steps where, initially, the polymer is degraded via $\mathrm{N}$-chlorination, through replacement of the hydrogen atom on amide nitrogen, followed by ring-chlorination via an irreversible intermolecular rearrangement called "Orton Rearrangement" (Barassi and Borrmann 2012). The amide skin layer is generally sensitive to chlorine attack since it is an electron-rich region. This phenomenon can be explained (Scheme 1b) as intra-molecular changes in PA caused by modification of hydrogen bonding due to the substitution of halogens in the amide ring. This reaction causes deformation and alteration in the chain structure of the PA skin layer, in turn causing defects in the membrane structure, which results in increased permeability but reduced selectivity or rejection. Scheme 1a, b represents the possible degradation and reaction mechanism of oxidative chain splitting in the PA layer by chlorination.

\section{X-ray diffraction analysis (XRD)}

The effective $d$-spacing indicates the existing space between the inter-segmental chains in the polymer matrix before and after modification. The X-ray diffractograms of pristine and modified RO membrane are shown in Fig. 6a, b. The XRD pattern of the unmodified membrane (Fig. 6a) shows crystalline nature and the presence of sharp peaks of diffraction was observed at $18^{\circ}, 24^{\circ}$, and $27^{\circ}$ on $2 \theta$ scale, respectively, signifying higher free volume in the polymer. From Fig. 6, an increase in $d$-spacing values of the same peaks could be observed from pristine to modified RO membrane, which gives a clear picture of the increasing amorphous nature post-chlorination. Therefore, from this critical observation, it can be concluded that pores of the membrane

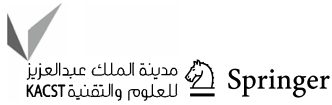




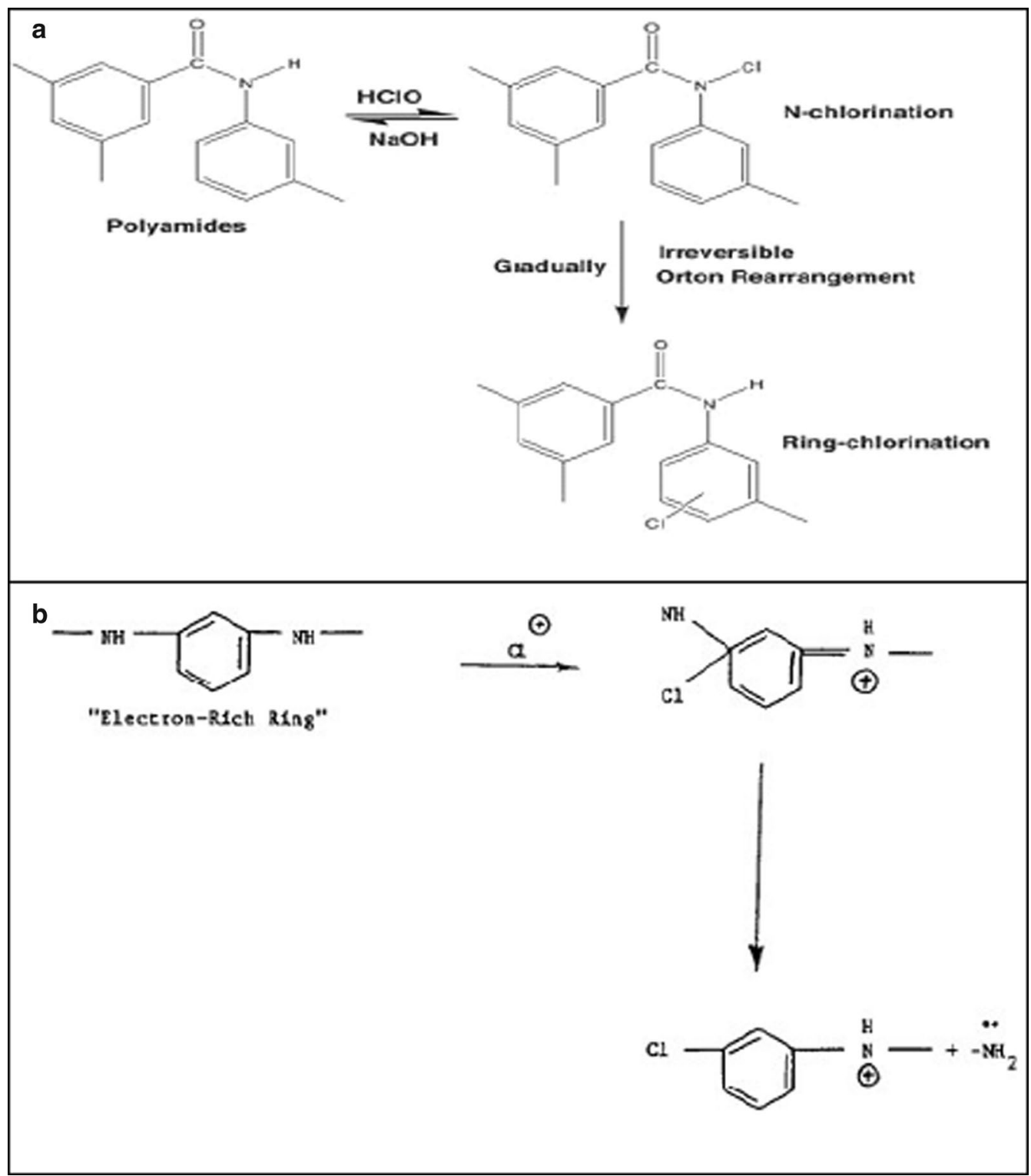

Scheme 1: a Degradation mechanism and $\mathbf{b}$ proposed reaction mechanism of oxidative chain splitting in PA by chlorination

were successfully modified from RO $(0.0001 \mu \mathrm{m})$ to $\mathrm{NF}$ $(0.0005 \mu \mathrm{m})$ size after chemical oxidation.

\section{Morphological studies}

Figure $7 \mathrm{a}-\mathrm{d}$ represents the surface and cross-sectional morphologies of the RO membrane before and after oxidation. Surface morphology of the pristine RO membrane (Fig. 7a) shows a smooth surface with no agglomeration of PA layer, whereas the modified ( $\mathrm{NaOCl}$ treated) $\mathrm{RO}$ membranes (Fig. 7c) display pores on the surface, which indicates that the $\mathrm{NaOCl}$ solution acts as an excellent pore opener via oxidation, thereby partially degrading the skin layer of RO membrane. On the other hand, the cross-sectional morphology shown in Fig. 7b pristine RO membrane illustrates the presence of a thin PA layer penetrating into the PES ultraporous layer followed by the polyester nonwoven support, whereas Fig. 7d reveals a much thinner skin layer on the ultraporous PES layer indicating a reduction in PA layer thickness.

\section{Experimental results}

\section{Effect of operating pressure on permeate flux and \% salt rejection}

The performance of the RO membrane modified to NF after 780 min of reaction time with $\mathrm{NaOCl}$ and UF after 


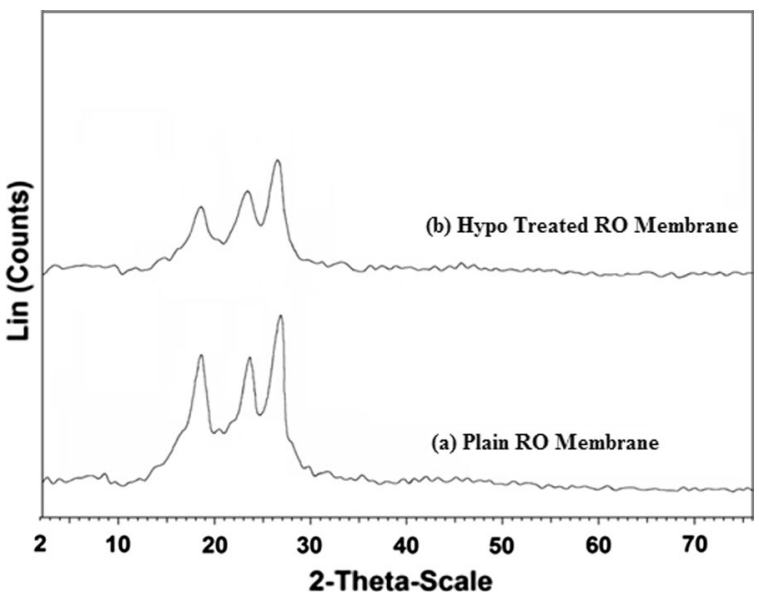

Fig. 6 X-ray diffraction spectra of a plain RO membrane and b hypotreated RO membrane

exposure time of $900 \mathrm{~min}$ was evaluated in terms of permeate water flux and \% salt rejection at various operating pressures. Figure 8 shows the water flux to increase linearly with rise in feed pressure from 0 to $7 \mathrm{~kg} / \mathrm{cm}^{2}$ for $\mathrm{NF}$ and 0 to $3 \mathrm{~kg} / \mathrm{cm}^{2}$ for UF membrane, respectively, after which no significant change was observed up to $9 \mathrm{~kg} / \mathrm{cm}^{2}$ for NF and $5 \mathrm{~kg} / \mathrm{cm}^{2}$ in case of UF. At applied pressures of 3 and $1 \mathrm{~kg} / \mathrm{cm}^{2}$, the flux values were found to be 56.25 , and $96.32 \mathrm{~L} / \mathrm{m}^{2} \mathrm{~h}$ for NF and UF, respectively, due to substantial TDS in feed water, implying requirement of higher applied pressure to oppose the natural osmotic pressure (Sridhar et al. 2002). The flux values increased from 3.5 to $113.5 \mathrm{~L} / \mathrm{m}^{2} \mathrm{~h}$, and 34.61 to $139.4 \mathrm{~L} / \mathrm{m}^{2} \mathrm{~h}$ when pressure was raised from 0 to $9 \mathrm{~kg} / \mathrm{cm}^{2}$ and 0 to $5 \mathrm{~kg} / \mathrm{cm}^{2}$ in case of NF and UF, respectively. The observations are attributed to the degradation of the PA layer, which allows water molecules to easily pass through the porous PES layer. A gradual enhancement in flux was observed at higher pressures owing to solution-diffusion mechanism of transport (Wijmans and Baker 1995; Ravikumar et al. 2014). On the laboratory scale, the $\%$ of salt rejection declined from 51.3 to $25.50 \%$ when trans-membrane pressure was varied from 0 to $9 \mathrm{~kg} / \mathrm{cm}^{2}$ for NF, since the flow rate of the small diaphragm pump of low capacity reduced due
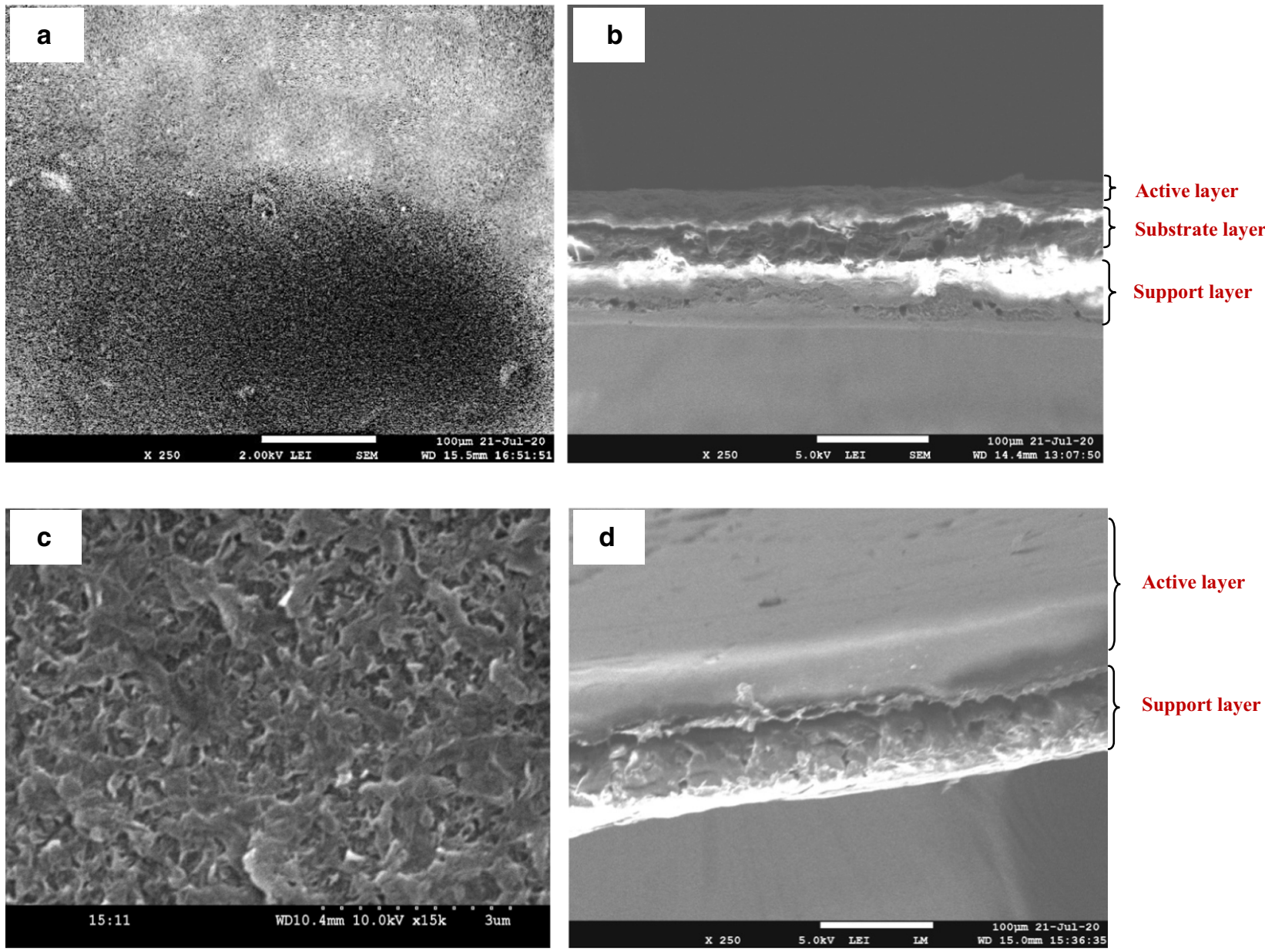

Fig. 7 SEM images of $\mathbf{a}$ surface and $\mathbf{b}$ cross section of pristine RO membrane, $\mathbf{c}$ surface and $\mathbf{d}$ cross section of hypo-treated RO membrane 


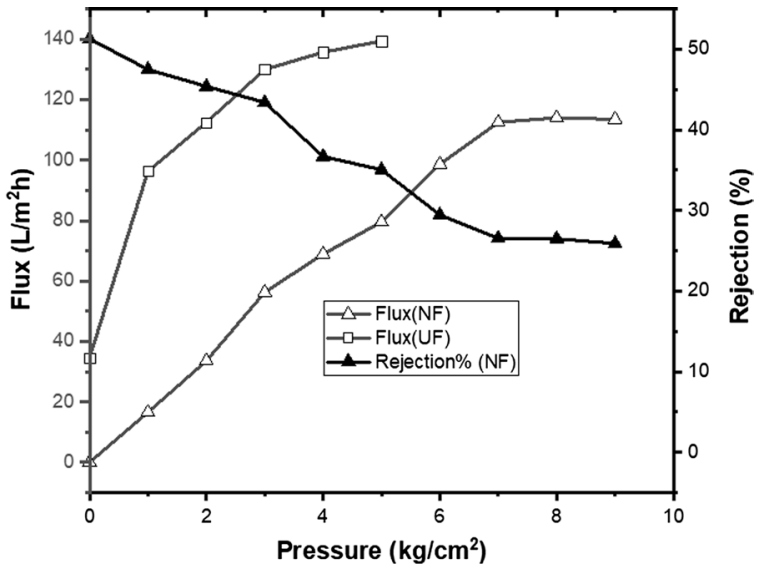

Fig. 8 Effect of operating pressure on flux and \% TDS rejection of NF membrane and UF flux

to greater throttle by reject needle valve at higher applied pressures. In contrast, on a pilot plant level, a multistage centrifugal pump can discharge feed water at the same flow rate against the applied pressure to achieve higher rejections with increasing pressure. Expectedly, the UF membrane exhibited a negligible change in $\%$ salt rejection as the pores became too large to prevent low molecular weight solutes and salts from passing through. Moreover, the rejection of salts through the negatively charged chlorinated membrane surface generally reduces (García et al. 2015). The hydrogen bonding of water molecules with amide moieties of polymer chain causes an increase in water flux in the permeate side (Matsuura and Sourirajan 1981). From the data obtained, the operating pressure of the experiments can be optimized to $7 \mathrm{~kg} / \mathrm{cm}^{2}$ for NF and $3 \mathrm{~kg} / \mathrm{cm}^{2} \mathrm{UF}$, but thereafter negligible changes were observed in flux and \% salt rejection.

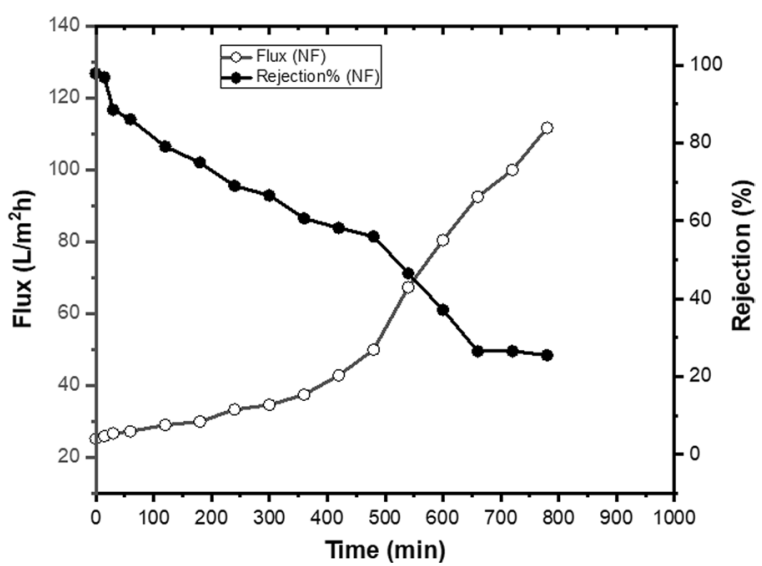

Fig. 9 Effect of $\mathrm{NaOCl}$ reaction time on flux and \% TDS rejection of nanofiltration membrane
Effect of $\mathrm{NaOCl}$ reaction time on permeate flux and \% salt rejection

From Fig. 9, a gradual enhancement in flux was observed from 25.22 for original $\mathrm{RO}$ membrane to $111.73 \mathrm{~L} / \mathrm{m}^{2} \mathrm{~h}$ for $\mathrm{NaOCl}$ treatment duration varying from 0 to $780 \mathrm{~min}$ in achieving NF membrane range of porosity. Enhancement in flux was observed due to enlargement in the pore size of the membrane. Further, the \% salt rejection was found to decline from 97.90 to $25.5 \%$. Chlorination of the membrane causes the deteriorating of $-\mathrm{H}$ bonds in the PA chain (García et al. 2015). At 780 min exposure time, rejection observed was only $25.5 \%$, depicting that the RO membrane had transformed into 400 Da MWCO region of NF. However, after $900 \mathrm{~min}$, the rejection was only $5.67 \%$ (not shown in figure), which reveals that the membrane pore size was reaching the borderline range between NF and UF (Ettori et al. 2011).

\section{Effect of $\mathrm{NaOCl}$ reaction time on permeate TDS}

The effect of operating time on permeate TDS for NF membrane at optimized pressure of $7 \mathrm{~kg} / \mathrm{cm}^{2}$, through chlorination of the used RO membrane, is represented in Fig. 10. An enhancement in permeate TDS from $9 \mathrm{ppm}$ for original RO membrane to $180 \mathrm{ppm}$ for $\mathrm{NF}$ was observed, when $\mathrm{NaOCl}$ reaction time was increased from 0 to $780 \mathrm{~min}$. Enhancement in permeate TDS confirms the opening of the RO membrane to attain porosity pertaining to NF region (Das et al. 2006; Rautenbach and Albrecht 1989). The permeate TDS increased with time, owing to the rejection of divalent ions as compared to monovalent ions, due to the induction of negatively charged chlorine ions on the membrane surface during the transformation process (Do et al. 2012).

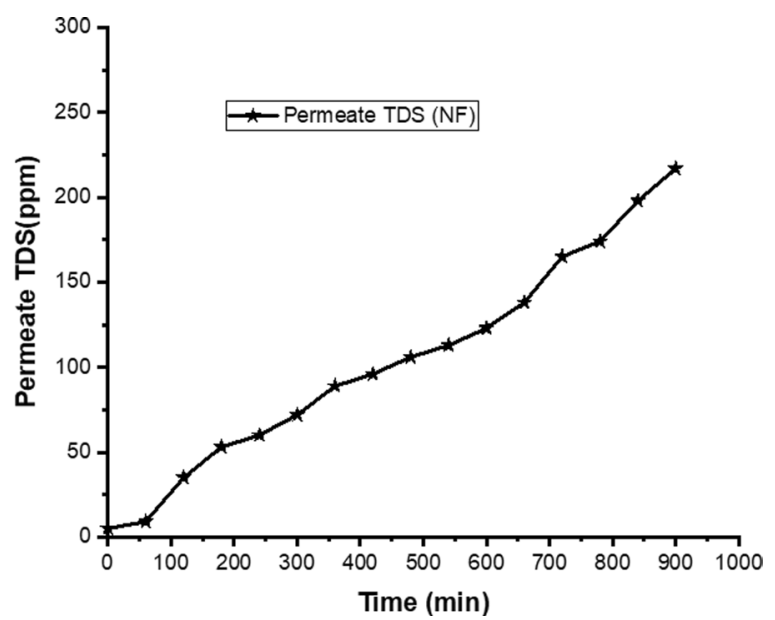

Fig. 10 Effect of $\mathrm{NaOCl}$ reaction time on permeate TDS of nanofiltration membrane 


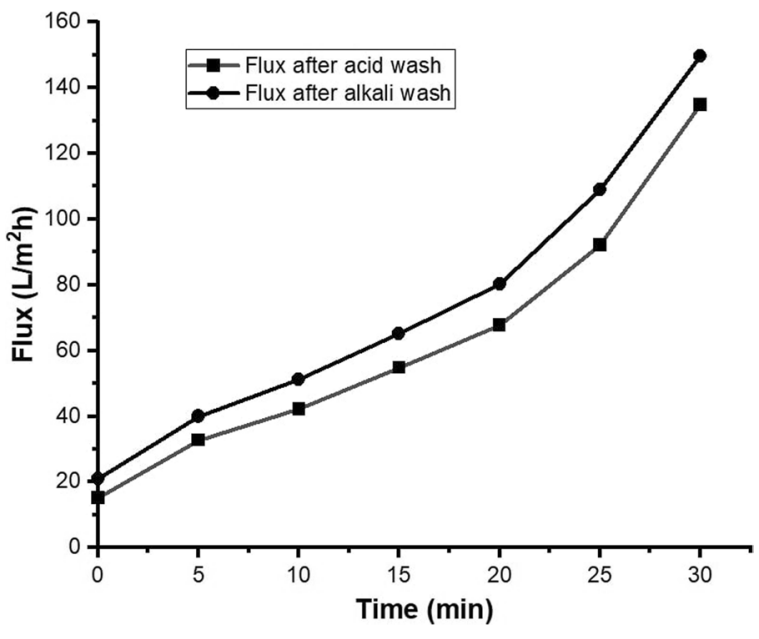

Fig. 11 Effect of chemical cleaning duration on flux of RO membrane modified by treatment with hypo for $900 \mathrm{~min}$

\section{Regeneration of modified membranes after washing}

Figure 11 represents restoration of flux with increasing duration of acid and alkaline washes of the RO membrane treated for $900 \mathrm{~min}$ to reach a borderline pore size zone between NF and UF (TDS rejection 5.67\%). The flux of the regenerated membrane increased from 15.25 to $134.81 \mathrm{~L} / \mathrm{m}^{2} \mathrm{~h}$ after acid wash and from 20.96 to $149.67 \mathrm{~L} / \mathrm{m}^{2} \mathrm{~h}$ following alkaline wash for $30 \mathrm{~min}$. From Fig. 11, it can be seen that the acidic and alkaline reagents used for membrane cleaning had successfully removed both inorganic and organic scales.

\section{Pilot-scale studies}

\section{Application of modified RO membrane for the production of packaged drinking water}

A pilot-scale study was performed using a RO membrane modified to NF range after 30-min exposure to hypo solution, for the treatment of surface water feed containing low TDS value. The produced drinking water obtained from the pilot plant was packed in bottles of $250 \mathrm{ml}, 500 \mathrm{ml}$ and $1 \mathrm{~L}$ capacities using a bottling unit capable of packaging water quantity of $5000 \mathrm{~L} /$ day. The process was coupled with pretreatment and post-treatment to achieve the required product water quality with TDS around $80 \mathrm{ppm}$. In the pre-treatment process, raw water with TDS $288 \mathrm{ppm}$ and $\mathrm{pH} 7.4$ was passed through a sand filter, activated carbon column, and a micron cartridge filter for pre-filtration, followed by a series of four NF membrane modules obtained by chemical modification of RO membranes. The NF membrane was able to partially remove soluble inorganic salts, especially hardness component comprising bivalent ions, and natural organic matter, but allowed sufficient minerals to pass through to the permeate side for human consumption. The purified water was then subjected to ultraviolet treatment to eliminate any residual bacterial contamination. Ozone was infused into the product tank to facilitate long term storage of the water by disinfection of all types of pathogens, if any, besides oxidation of insoluble contaminants. Figure 12a illustrates the schematic of the NF water purification pilot plant along with the bottling unit. The water was tested for 85 parameters, including heavy metal ions, pesticides, and pathogens, to confirm potable nature before packaging. TDS was maintained in the range $80-150 \mathrm{ppm}$ to provide a balance between good taste and content of important minerals for drinking purpose.

\section{Description of bottling unit for the production of packaged drinking water}

The purified mineral enriched water was packed under hygienic conditions into water bottles of varying capacities through an automatic rinsing, filling, and capping machine. The bottling unit comprised a manual empty bottle feeding unit, take-up section, rinsing section, filling assembly, capping, and inspection screen for quality control. Before bottling, the product water was stored in a stainless steel intermediate tank of $60 \mathrm{~L}$ capacity and fed by an automatic booster pump. A $0.5-\mu \mathrm{m}$-size jumbo cartridge was provided in the discharge line of the booster pump to ensure that no dust would enter into the bottled water. The bottles are passed through the belt conveyor having an inline air compressor to suck bottles inside the bottling machine. Inside the machine, bottles were washed by product water, by flushing with a centrifugal pump of 1 horsepower (HP) capacity. The water was filled into the bottles by passing it through four nozzles simultaneously up to the desired quantity as indicated by a sensor. After filling, the bottles are capped by a vibrator and further sealed with a punching rod. The sealed bottles passed through a belt for screening and, finally, labeling and marking of maximum retail price (MRP) with batch number and date, were completed. The unit is versatile in manufacturing packaged drinking water of varying capacities such as $250 \mathrm{~mL}, 500 \mathrm{~mL}$, and $1 \mathrm{~L}$ @ 5000 L/day. Figures $12 \mathrm{~b}$ and 13 represent the photographic depiction of the bottling unit, production and distribution of packaged drinking water of various brands marketed by dealers.

\section{Cost estimation for production of packaged drinking water}

The cost estimation for the processing of NF permeate into packaged drinking water is provided in Table 2 . The major factors considered for estimation of the total capital

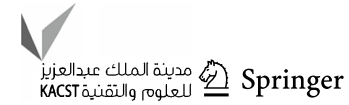




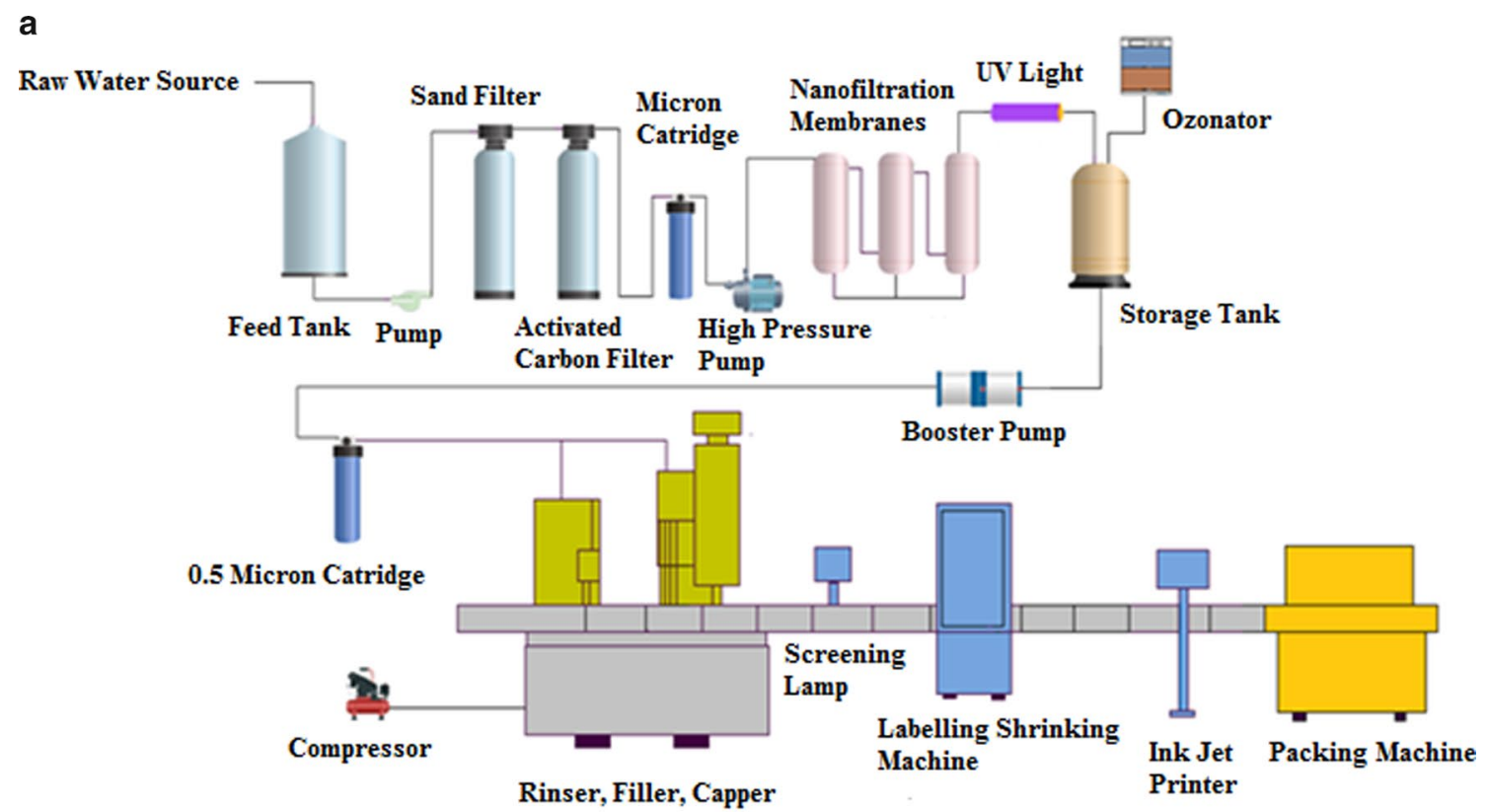

b

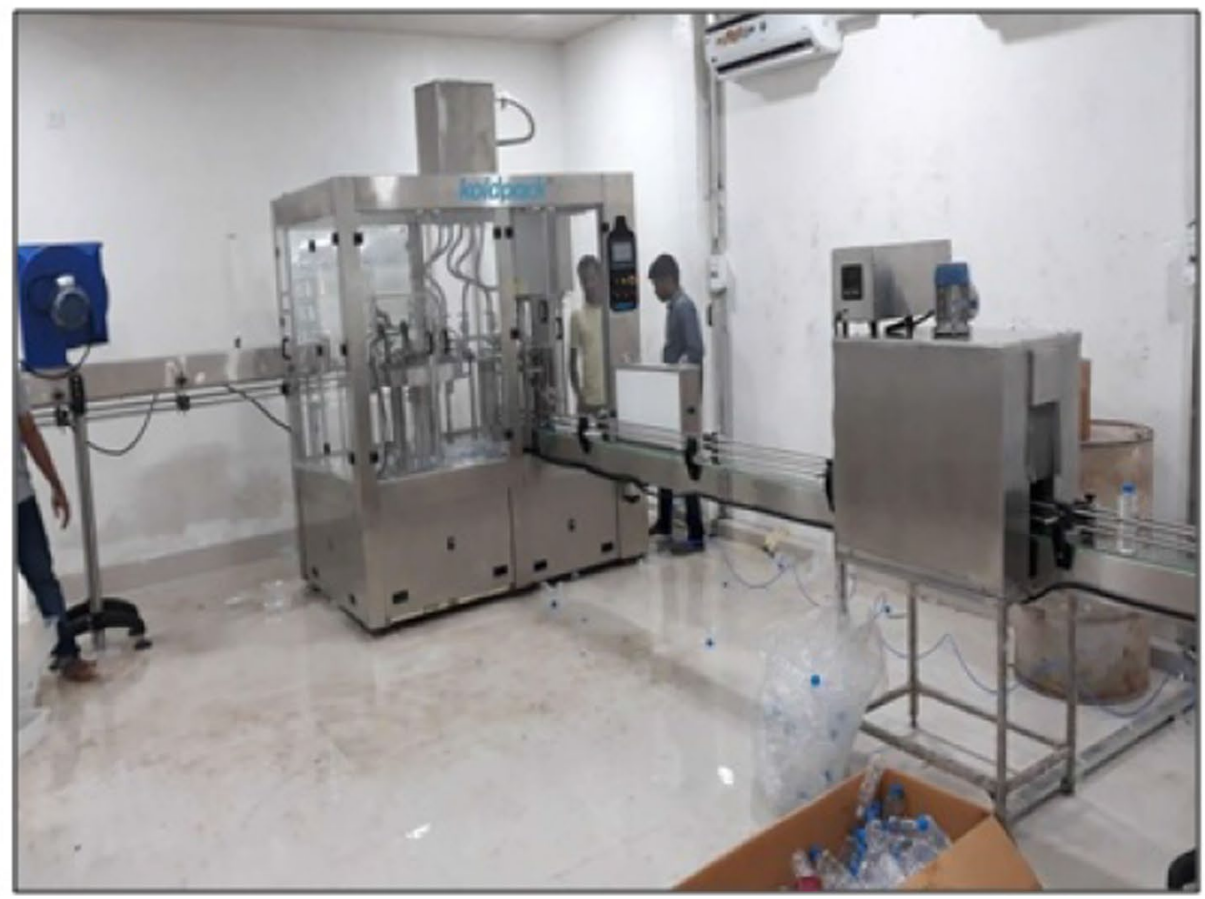

Fig. 12 Schematic of $\mathbf{a}$ water purification pilot plant along with bottling unit and $\mathbf{b}$ photograph of bottling unit

investment of the pilot plant include the costs of fixed capital, working capital, besides operation and maintenance. It includes cost components of direct production, fixed overhead plant charges, administrative work, distribution, and marketing expenses. The detailed cost estimation for the processing of raw water was calculated by considering a NF plant capacity of $1000 \mathrm{~L} / \mathrm{h}$. When the operation time was considered as $20 \mathrm{~h}$ per day, the replacement of the membrane module would be required after a life span of 3 years. The operating cost of water was found to be 0.0032 USD/L of purified water generated. Further, the detailed cost estimation for the production of packaged drinking water by the bottling unit consists of costs of power consumption, construction and engineering materials, pre-filter cartridges, manpower, raw water, machinery, certification, water analysis, and rent on space as shown in Table 3. The pilot plant 


\section{(BIS Certified ISI Mark CML 6300052694; FSSAI 10. 13618012000397)}

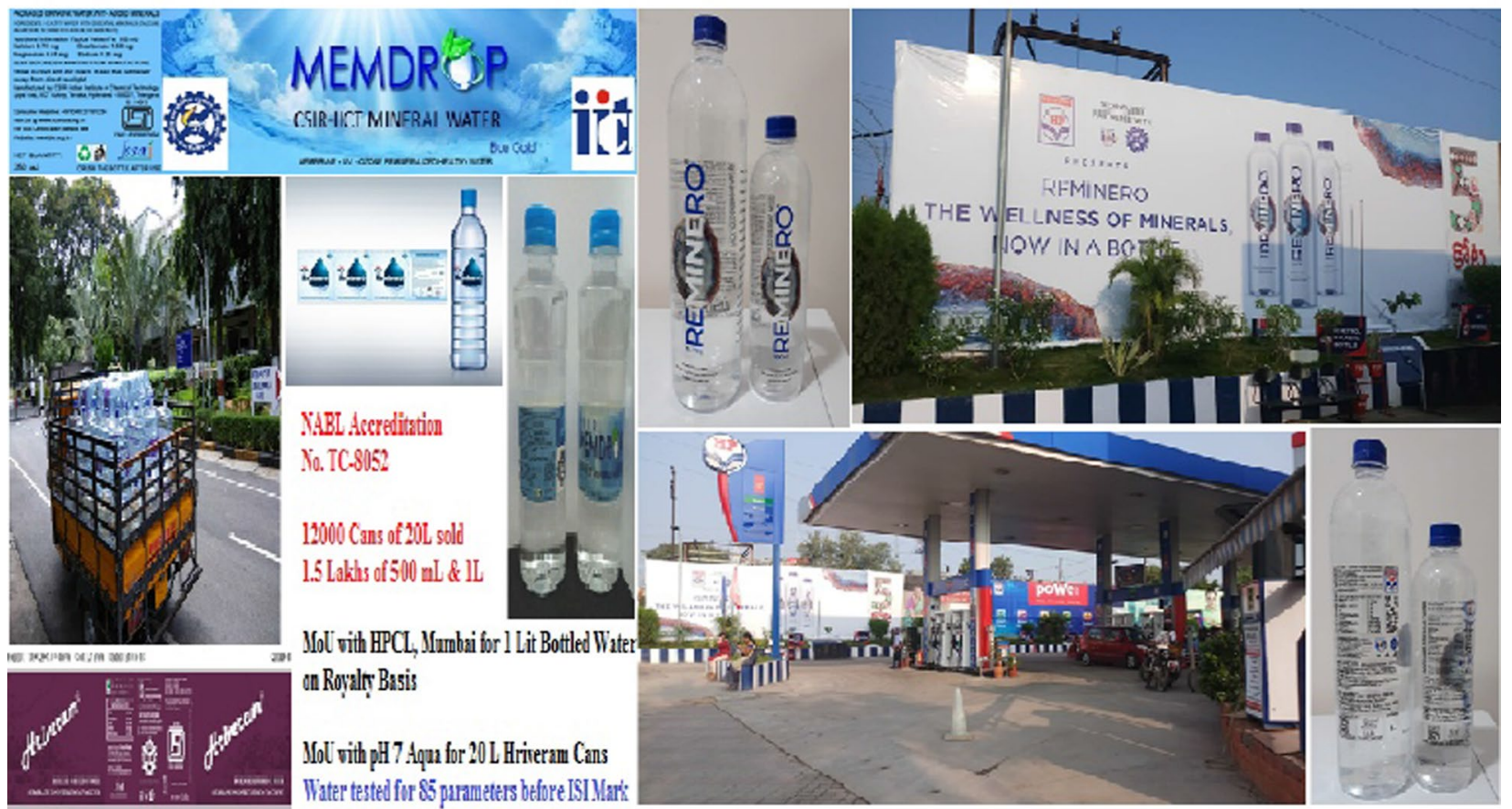

Fig. 13 Photographs of production and distribution of packaged drinking water of various brands

produces $5000 \mathrm{~L} /$ day of packaged drinking water, and feed capacity to the bottling unit was assumed to be $5000 \mathrm{~L} /$ day. The depreciation based on lifespan of hardware was taken as 10 years, and interest on capital was considered to be $10 \%$. NF permeate cost per liter was determined to be about 0.0032 USD, with 0.41 years as payback period.

\section{Conclusions}

The membrane was successfully treated with hypo solution, and the experiments were conducted on a laboratory scale to optimize various parameters including pressure and time of hypo solution exposure. During modification of RO membrane to NF range of porosity, a flux of $25.2-111.7$ was observed with decreasing rejection of TDS from 97.90 to $25.5 \%$ across an NaOCL exposure duration of $0-780 \mathrm{~min}$. A reaction time of $\geq 900$ min was necessary for nearing UF range of pore size by complete degradation of the PA layer for attaining negligible TDS rejection with maximum flux. From the experiments, it was confirmed that the chemical modification of RO membrane to NF pore size was highly effective in the treatment of surface water with low TDS of $150-400 \mathrm{ppm}$ and ground water with moderate TDS of 400-700 ppm. Hence, the approach to modify used RO membranes to functionalized NF membrane is more economical and viable than purchase of commercially available PA NF membranes. Also, $\mathrm{ClO}_{2}$ proved to be a safe disinfectant for the removal of biofouling without degrading the PA NF layer as it does not generate free chlorine in aqueous solutions. The process was successfully scaled up to the commercial level for the production of packaged drinking water with sufficient mineral content and acceptable taste. 
Table 2 Detailed cost estimation for processing of water through modified RO membrane (nanofiltration)

\begin{tabular}{|c|c|c|c|c|c|c|c|}
\hline $1 \mathrm{HP}$ & 0.74 & $\mathrm{~kW}$ & & & & & \\
\hline USD & 76.25 & Rs & & & & & \\
\hline \multicolumn{8}{|l|}{ Raw water cost (0.16 Rs./L) } \\
\hline Total no of working hours & 20 & & & & & & \\
\hline $\begin{array}{l}\text { Membrane area( } 4 " \text { dia } \times 40^{\prime \prime} \\
\text { length module }), \mathrm{m}^{2}\end{array}$ & 7.5 & & & & & & \\
\hline Total membrane area, $\mathrm{m}^{2}$ & 37.5 & Capital cost (Rs.) & Rs.(h) & Rs. (day) & USD (h) & USD (day) & USD (Yr) \\
\hline Power (Rs.6/unit) & $\begin{array}{l}\text { Feed pump-0.5HP } \\
\text { Dosing system- } 0.025 \mathrm{HP} \\
\text { High-pressure pump-3HP }\end{array}$ & & 15.75 & 315.13 & 0.21 & 4.13 & 1508.52 \\
\hline Membrane replacement & Life-3 years & 62,500 & 2.85 & 57.07 & 0.04 & 0.75 & 273.22 \\
\hline chemicals & For cleaning, dosing, storage, UV & & 7.42 & 148.41 & 0.10 & 1.95 & 710.42 \\
\hline Pre-filter cartridge replacement & Activated carbon, micron filter & 1200 & 0.67 & 6.67 & 0.01 & 0.09 & 31.91 \\
\hline Utilities & Raw water & & 192 & 3840 & 2.52 & 50.36 & $18,381.4$ \\
\hline Labor & For operation and maintenance & & 15 & 300 & 0.20 & 3.93 & 1436.07 \\
\hline $\begin{array}{l}\text { Depreciation cost and interest on } \\
\text { capital (USD) }\end{array}$ & $20 \%$ (10\% each) & 350,000 & 4590.20 & & & 2.52 & 918.03 \\
\hline Total operating investment & & & & & & & $23,259.57$ \\
\hline $\begin{array}{l}\text { Total purified water generated per } \\
\text { year(L) }\end{array}$ & & & & & & & $7,300,000$ \\
\hline \multirow{2}{*}{$\begin{array}{l}\text { Cost of purified water generated } \\
\text { (USD) }\end{array}$} & & & & & & & 0.003186 \\
\hline & & & & & & Rs./L & 0.243 \\
\hline If sold at $0.0045 \mathrm{USD} / \mathrm{L}$ & & & & & & & 32,850 \\
\hline Annual profit (USD) & & & & & & & 9590.43 \\
\hline Payback period (year) & & & & & & & 0.41 \\
\hline
\end{tabular}

Table 3 Detailed cost estimation of pilot plant for production of packaged drinking water@5000 L/day

\begin{tabular}{ll}
\hline Cost per liter of water production & \\
\hline (1) Raw water cost per liter & 0.16 \\
\hline (2) Electricity/maintenance etc & 0.12 \\
(3) Manpower cost & 0.23 \\
(4) Installation cost & 2.34 \\
Total cost & 2.85 \\
Details & 5000 \\
Capacity (C) (liter/day) & 26 \\
No. of working days per month (d) & 12 \\
No. of months in a year (N) & \\
Component & 0.16 \\
(1) Raw water cost (RW) & \\
Raw water cost per liter & \\
(2) Electricity/maintenance etc & \\
(a) Power cost (P) & 14.25 \\
Power consumption (kWh) & 570 \\
Power cost (@ Rs. 8/per unit) & 0.11 \\
Power consumption per liter & \\
(b) Power for lighting & 43 \\
No. of ceiling lights (NL) & 7.5 \\
Power consumption per each light (pl) (watt) & 4 \\
No. of flycatchers (FC) &
\end{tabular}


Table 3 (continued)

\begin{tabular}{|c|c|}
\hline \multicolumn{2}{|l|}{ Cost per liter of water production } \\
\hline (1) Raw water cost per liter & 0.16 \\
\hline Power consumption per each flycatcher (PFC) (Watt) & 25 \\
\hline Total power consumption $(\mathrm{kWh})(\mathrm{TPC})=(\mathrm{nl} \times \mathrm{pl}+\mathrm{PFC} \times \mathrm{FC}) / 1000$ & 0.42 \\
\hline 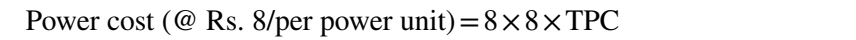 & 27.07 \\
\hline Power consumption per liter $=8 \times 8 \times \mathrm{TPC} / 5000$ & 0.0054 \\
\hline Sub-total & 0.12 \\
\hline \multicolumn{2}{|l|}{ (3) Manpower } \\
\hline No. of manpower (NMP) & 2 \\
\hline Monthly salary (MS) (Rs.) & 15,000 \\
\hline Manpower cost per liter of water production $=\mathrm{MS} /(C \times d)$ & 0.23 \\
\hline \multicolumn{2}{|l|}{ (a) CAPEX } \\
\hline CAPEX including plant layout (CC) & $9,720,000$ \\
\hline Capex appropriated for 1 year taking life cycle $(\mathrm{n})$ of 7 years $=(\mathrm{CC} / n)$ & $1,388,571.43$ \\
\hline Interest on Capex appropriated for 1 year $(@ 7 \%)=(I / n)$ & 97,200 \\
\hline Costing per liter of permeate $=((\mathrm{CC}+I) / n)) \times(1 /(C \times d \times N))$ & 0.952 \\
\hline \multicolumn{2}{|l|}{ (b) Certification and Training cost } \\
\hline Certification (BIS + FSSAI etc.) for 1 year $(S)$ & 150,000 \\
\hline Training for 1 year (Rs 9 lakhs/7 years) $(T)$ & $128,571.42$ \\
\hline Sub-total $=150,000+128,571.4$ & $278,571.42$ \\
\hline Costing per liter of permeate $=(s+t) /(c \times d \times n)$ & 0.18 \\
\hline \multicolumn{2}{|l|}{ (c)Water analysis (WM) } \\
\hline Analytical cost per liter & 0.1 \\
\hline \multicolumn{2}{|l|}{ (d) Rent on space } \\
\hline Total space (Sq.ft) & 1450 \\
\hline Cost per Sq.ft per month & 100 \\
\hline Rent on space per month $(R)$ & 145,000 \\
\hline Rent on space per liter $=R /(C \times d)$ & 1.11 \\
\hline Sub-total & 2.34 \\
\hline Total cost per liter $=(1+2+3+4)$ & 2.85 \\
\hline Profit margin per liter of water sold & 1 \\
\hline Total cost per liter (Rs.) & 3.85(USD) \\
\hline
\end{tabular}

Acknowledgements The authors acknowledge the Director, CSIRIndian Institute of chemical technology, for supporting this research work of communication no. IICT/Pubs./2020/101.

Funding The research work was funded by the Council of Scientific and Industrial Research, New Delhi, India, under Grant code: GAP0710.

\section{Compliance with ethical standards}

Conflict of interests All authors have seen and approved the manuscript being submitted. Hence, on behalf of all authors, the corresponding author states that there is no conflict of interest.

Informed consent Informed consent was obtained from all individual participants included in the study.

Open Access This article is licensed under a Creative Commons Attribution 4.0 International License, which permits use, sharing, adaptation, distribution and reproduction in any medium or format, as long as you give appropriate credit to the original author(s) and the source, provide a link to the Creative Commons licence, and indicate if changes were made. The images or other third party material in this article are included in the article's Creative Commons licence, unless indicated otherwise in a credit line to the material. If material is not included in the article's Creative Commons licence and your intended use is not permitted by statutory regulation or exceeds the permitted use, you will need to obtain permission directly from the copyright holder. To view a copy of this licence, visit http://creativecommons .org/licenses/by/4.0/.

\section{References}

Barassi G, Borrmann T (2012) N-chlorination and Orton rearrangement of aromatic polyamides. J Memb Sci 2(2):1000115. https:// doi.org/10.4172/2155-9589.1000115

Buelke C, Alshami A, Casler J, Lewis J, Al-Sayaghi M, Hickner MA (2018) Graphene oxide membranes for enhancing water 
purification in terrestrial and space-born applications: state of the art. Desalination 448:113-132. https://doi.org/10.1016/j.desal 2018.09.008

Coutinho de Paula E, Gomes JCL, Amaral MCS (2017) Recycling of end-of-life reverse osmosis membranes by oxidative treatment: a technical evaluation. Water Sci Technol 76(3):605-622. https:// doi.org/10.2166/wst.2017.238

Das C, Patel P, De S, Das Gupta S (2006) Treatment of tanning effluent using nanofiltration followed by reverse osmosis. Sep Purif Technol 50(3):291-299. https://doi.org/10.1016/j.seppur.2005.11.034

Do VT, Tang CY, Reinhard M, Leckie JO (2012) Degradation of polyamide Nanofiltration and reverse osmosis membranes by hypochlorite. Environ Sci Technol 46(2):852-859. https://doi. org/10.1021/es203090y

El Aassar AHMA (2012) Polyamide thin-film composite membranes using interfacial polymerization: synthesis, characterization, and reverse osmosis performance for water desalination. Aust J Basic Appl Sci 6(6):382-439

Ettori A, Gaudichet ME, Schrotter JC, Aimar P, Causserand C (2011) Permeability and chemical analysis of aromatic polyamide-based membranes exposed to sodium hypochlorite. J Memb Sci 375(1-2):220-230. https://doi.org/10.1016/j.memsc i. 2011.03 .044

García PR, Landaburu AJ, Molina S, Rodríguez SL, Teli SB, García CE (2015) Transformation of end-of-life RO membranes into NF and UF membranes: evaluation of membrane performance. J Memb Sci 495:305-315. https://doi.org/10.1021/es203090y

Gohil JM, Suresh AK (2017) Chlorine attack on reverse osmosis membranes: mechanisms and mitigation strategies. J Memb Sci 541:108-126. https://doi.org/10.1016/j.memsci2017.06

Kang GD, Gao CJ, Chen WD, Jie XM, Cao YM, Yuan Q (2007) Study on hypochlorite degradation of aromatic polyamide reverse osmosis membrane. J Memb Sci 300(1-2):165-171. https://doi.org/10.1016/j.memsci.2007.05.025

Lawler W, Bradford HZ, Cran MJ, Duke M, Leslie G, Ladewig BP, Le CP (2012) Towards new opportunities for reuse, recycling, and disposal of used reverse osmosis membranes. Desalination 299:103-112

Le NL, Nunes SP (2016) Materials and membrane technologies for water and energy sustainability. Sustain Mater Technol 7:1-28. https://doi.org/10.1016/j.susmat.2016.02.001

Lee KP, Arnot TC, Mattia D (2011) A review of reverse osmosis membrane materials for desalination-development to date and future potential. J Memb Sci 370(1-2):1-22

Li Y, Su Y, Dong Y, Zhao X, Jiang Z, Zhang R, Zhao J (2014) Separation performance of thin-film composite Nano filtration membrane through interfacial polymerization using different amine monomers. Desalination 333(1):59-65. https://doi. org/10.1016/j.desal.2013.11.035

Maddah HA, Alzhrani AS, Bassyouni M, Abdel-Aziz MH, Zoromba M, Almalki AM (2018) Evaluation of various membrane filtration modules for the treatment of seawater. Appl Water Sci 8:150. https ://doi.org/10.1007/s13201-018-0793-8

Matsuura T, Sourirajan S (1981) Reverse osmosis transport through capillary pores under the influence of surface forces. Ind Eng Chem Res 20(2):273-282. https://doi.org/10.1021/i200013a015

Mohammad AW, Teow Y, Ang W, Chung Y, Oatley RD, Hilal N (2015) Nano filtration membranes review: recent advances and future prospects. Desalination 356:226-254. https://doi.org/10.1016/j. desal.2014.10.043

Molina S, García-Pacheco R, Rodríguez-Sáez L, García-Calvo E, Campos E, Martinez DZ, Campa JG, Abajo J (2015) Transformation of end-of-life RO membranes into recycled NF and UF membranes: surface characterization. In: The International
Desalination Association (IDA) World Congress Proceedings, San Diego (15WC-51551)

Molina S, Landaburu-Aguirre J, Rodríguez-Saez L, García-Pacheco R, Campa JG, García-Calvo E (2018) Effect of sodium hypochlorite exposure on polysulfone recycled UF membranes and their surface characterization. Polym Degrad Stab 150:46-56. https://doi. org/10.1016/j.polymdegradstab.2018.02.012

Moradi MR, Pihlajamaki A, Hesampour M, Ahlgren J, Manttan M (2019) End-of-life RO membranes recycling: reuse as NF membranes by polyelectrolyte layer-by-layer deposition. J Memb Sci 584:300-308. https://doi.org/10.1016/j.memsci.2019.04.060

Moron-Lopez J, Nieto-Reeyes L, Aguado S, Ei-Shehawy R, Molina S (2019) Recycling of end-of-life reverse osmosis membranes for membrane biofilm reactors (MBfRs). Effect of chlorination on the membrane surface and gas permeability. Chemosphere 231:103-112. https://doi.org/10.1016/j.chemosphere.2019.05.108

Moshe H, Menachem E (2007) Bio-fouling of reverse osmosis membranes: role of biofilm-enhanced osmotic pressure. J Memb Sci 295(1-2):11-20. https://doi.org/10.1016/j.memsci.2007.02.024

Pangarkar BL, Sane MG, Guddad M (2011) Reverse osmosis and membrane distillation for desalination of groundwater: a review. ISRN Mater Sci. https://doi.org/10.5402/2011/523124

Porubská M, Szöllős O, Kóňová A, Janigová I, Jašková M, Jomová K, Chodák I (2012) FTIR spectroscopy study of polyamide-6 irradiated by electron and proton beams. Polym Degrad Stab 97(4):523531. https://doi.org/10.1016/j.polymdegradstab.2012.01.017

Puspitasari V, Granville A, Le-Clech P, Chen V (2010) Cleaning and aging effect of sodium hypochlorite on polyvinylidene fluoride (PVDF) membrane. Sep Purif Technol 72(3):301-308. https:// doi.org/10.1016/j.seppur.2010.03.001

Rautenbach R, Albrecht R (1989) Membrane processes. Wiley, Chichester

Ravikumar YVL, Kalyani S, Satyanarayana SV, Sridhar S (2014) Processing of pharmaceutical effluent condensate by Nano filtration and reverse osmosis membrane techniques. J Taiwan Inst Chem Eng 45(1):50-56. https://doi.org/10.1016/j.jtice.2013.09.021

Razdan U, Shah V (2001) Nanofiltration membranes as a suitable alternative to reverse osmosis ultrafiltration membranes in separation processes. J Sci Ind Res India 60(7):560-563

Sridhar S (2018) Membrane technology: sustainable solutions in water, health, energy, and environmental sectors. CRC Press, Boca Raton

Sridhar S, Kale A, Khan A (2002) Reverse osmosis of edible vegetable oil industry effluent. J Memb Sci 205(1-2):83-90. https://doi. org/10.1016/S0376-7388(02)00065-0

Tin P, Chung T, Liu Y, Wang R, Liu S, Pramoda K (2003) Effects of cross-linking modification on the gas separation performance of Matrimid membranes. J Memb Sci 225(1-2):77-90. https://doi. org/10.1016/j.memsci.2003.08.005

Venkata SB, Madhumala M, Prakasham R, Sridhar S (2016) Processing of biscuit industrial effluent using thin-film composite Nanofiltration membranes. Des Monomers Polym 19(1):47-55. https://doi. org/10.1080/15685551.2015.1092012

Warsinger DM, Chakraborty S, Tow EW, Plumlee MH, Bellona C, Loutatidou S, Ghassemi A (2018) A review of polymeric membranes and processes for potable water reuse. Prog Polym Sci 81:209-237. https://doi.org/10.1016/j.progpolymsci.2018.01.004

Wijmans JG, Baker RW (1995) The solution-diffusion model: a review. J Memb Sci 107:1-21. https://doi.org/10.1016/03767388(95)00102-I

Will L, Alice A, Marlene DC, Greg L, Le-Clech P (2013) Production and characterization of UF membranes by chemical conversion of used RO membranes. J Memb Sci 447:203-211. https://doi. org/10.1016/j.memsci.2013.07.015 
Zhou W, Song L (2005) Experimental study of water and salt fluxes through reverse osmosis membranes. Environ Sci Technol 39:3382-3387. https://doi.org/10.1021/es0403561

Zi Y, Yi Z, Zhiyuan F, Xiaobo R, Tong Zh, Zhien Z (2019) A Review on reverse osmosis and nano filtration membranes for water purification. Polymers (Basel) 11:1252. https://doi.org/10.3390/ polym11081252

Publisher's Note Springer Nature remains neutral with regard to jurisdictional claims in published maps and institutional affiliations. 